\title{
Lane Tracking pada Robot Beroda Holonomic menggunakan Pengolahan Citra
}

\author{
ALI RIZAL CHAIDIR, KHAIRUL ANAM, GAMMA ADITYA RAHARDI
}

\author{
Fakultas Teknik Universitas Jember, Indonesia \\ Email: ali.rizal@unej.ac.id
}

Received 6 Agustus 2019 | Revised 3 September 2019 | Accepted 11 Oktober 2019

\begin{abstract}
ABSTRAK
Robot merupakan teknologi yang dapat diterapkan bidang pertanian dan industri. Salah satu teknik navigasi robot yang dapat diterapkan di bidang pertanian dan industri adalah lane tracking. Untuk bernavigasi robot membutuhkan sebuah alat untuk mengenali lingkungannya, alat tersebut dapat berupa sensor atau kamera. Salah satu kelebihan menggunakan kamera jika dibandingkan dengan sensor adalah dapat mengurangi penggunaan perangkat keras untuk mengenali lingkungan robot. Fokus utama penelitian ini adalah membuat robot beroda holonomic untuk bernavigasi di antara dua garis yang berada di sebelah kiri dan kanan robot menggunakan kamera. Kamera digunakan untuk menangkap citra di depan robot, citra tersebut diolah disebuah SBC (Single Board Computer) untuk mendapatkan parameter jumlah pixel antara garis tengah robot dengan garis sebelah kanan dan kiri robot. Parameter tersebut kemudian diolah untuk menentukan kecepatan motor pada roda robot holonomic. Hasil yang diperoleh adalah dari setiap pengujian robot mampu bernavigasi pada jalur yang telah ditentukan.
\end{abstract}

Kata kunci: Lane Tracking, Pengolahan Citra, Robot Beroda Holonomic

\begin{abstract}
Robotic navigation techniques that can be applied in agriculture and industry is lane tracking. To navigate, robots need device to recognize the environment, the device can use sensors or cameras. The main focus of this research is to make holonomic wheeled robot to navigate between two lines located on the left and right of the robot using the camera. The camera is used to capture the image in front of the robot, the image is processed in an SBC (Single Board Computer) to get the paramters of the number of pixels between the center line with the right and left lines of the robot. These paramaters are the processed to determine the motor speed on the holonomic robot wheel. The result of each test is that the robot is able to navigate on a predetermined path.
\end{abstract}

Keywords: Lane Tracking, Image Processing, Holonomic Wheeled Robot 


\section{PENDAhuluan}

Kemajuan suatu negara dapat dilihat dari perkembangan teknologi yang dihasilkan oleh negara tersebut, teknologi dapat mempercepat dan mempermudah tercapainya suatu tujuan tertentu, salah satu teknologi yang dapat membantu dan menggantikan beberapa tugas manusia yang sederhana adalah robotika (Siciliano \& Khatib, 2008). Robot dapat bergerak secara mandiri, berdasarkan perintah operator (Chaidir, Satriya, \& Kalandro, 2016), dan dapat dilakukan dengan menggunakan teknik pengindraan visual. Dengan menggunakan teknik pengindraan visual dalam proses navigasi robot maka robot tidak membutuhkan banyak sensor untuk navigasi, karena dengan menggunakan pengindraan visual (menggunakan kamera webcam) dapat mengetahui posisi (Chaidir, Muldayani, \& Kalandro, 2018), jarak, warna, dan bentuk dari suatu objek yang ada di lingkungan robot.

Robot dapat diterapkan di bidang transportasi, industri (Siciliano \& Khatib, 2008) dan pertanian (Hassan, Ullah, \& Iqbal, 2016) (Umarkar \& Karwankar, 2016). Salah satu jenis robot yang dapat diterapkan di bidang tersebut adalah robot beroda dengan gerakan holonomic. Berbeda dengan gerakan berbelok robot jenis car like mobile robot (Fahmizal, Murti, \& Pratama, 2018), gerakan holonomic adalah sebuah gerakan yang membuat robot tidak perlu mengubah arah hadapnya. Gerakan robot tersebut dapat dilakukan dengan menggunakan roda omni, yaitu 3 buah roda omni dengan posisi setiap roda seperti yang ditunjukkan pada Gambar 2 (McComb, 2011).

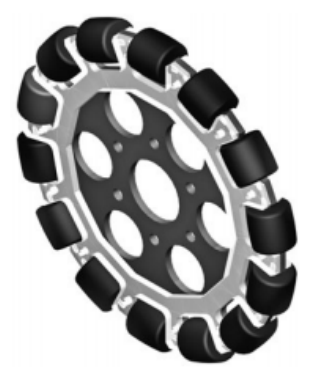

Gambar 1. Roda Omni

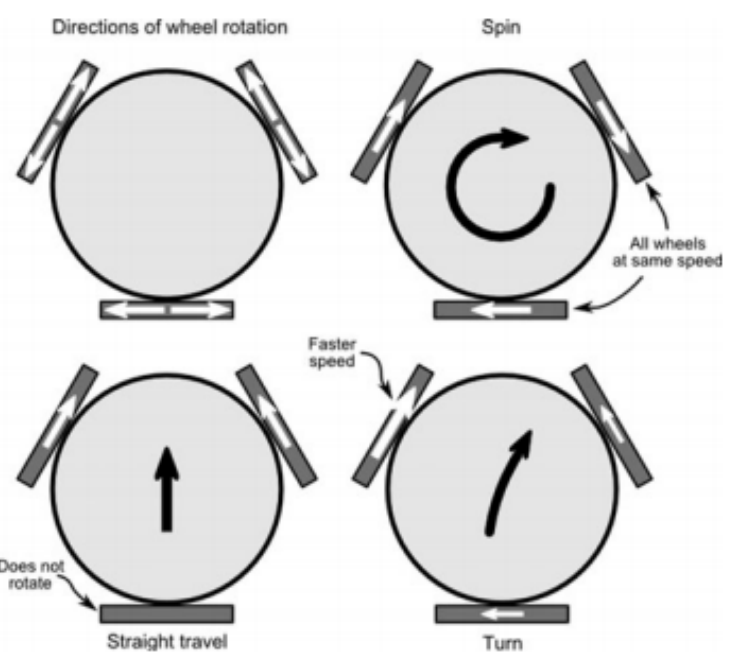

Gambar 2. Posisi Roda Robot Beroda Holonomic 
Robot membutuhkan teknik navigasi untuk menyelesaikan tugasnya, salah satu teknik navigasi pada robot beroda adalah lane tracking. Lane tracking adalah sebuah algoritma untuk membantu sebuah robot atau kendaraan untuk mengikuti sebuah jalur berupa sebuah lorong atau sejenisnya, tidak hanya untuk robot beroda, lane tracking juga dapat diaplikasikan untuk quadcopter (Ko, Oh, \& Ahn, 2016). Lane tracking tidak hanya dapat diterapkan di bidang pertanian, lane tracking pada umumnya diterapkan pada sistem transportasi cerdas, atau kendaraan transportasi yang bergerak secara mandiri (Bounini, Gingras, Lapointe, \& Pollart, 2015) (Yoo, Yang, \& Sohn, 2013).

Fokus penelitian ini adalah membuat robot beroda holonomic agar dapat bernavigasi di antara dua garis yang berada di sebelah kiri dan kanan robot menggunakan kamera. Kamera digunakan untuk menangkap citra di depan robot, citra tersebut diolah di sebuah SBC (Single Board Computer) untuk mendapatkan parameter jumlah pixel antara garis tengah robot dengan garis sebelah kanan dan kiri robot. Parameter tersebut kemudian diolah untuk menentukan kecepatan motor pada setiap roda robot holonomic agar robot dapat bergerak maju, dan berbelok.

\section{METODOLOGI}

\subsection{Desain Sistem Keseluruhan}

Desain sistem terdiri dari dua bagian, yaitu desain alur proses dari perangkat keras robot (Gambar 3) dan desain alur proses dari algoritma pengolahan citra (Gambar 4). Ada tiga komponen utama di dalam sistem perangkat keras, yaitu webcam untuk mengambil citra, LattePanda sebagai Single Board Computer untuk pengolahan citra, dan driver motor untuk mengendalikan motor DC pada robot.
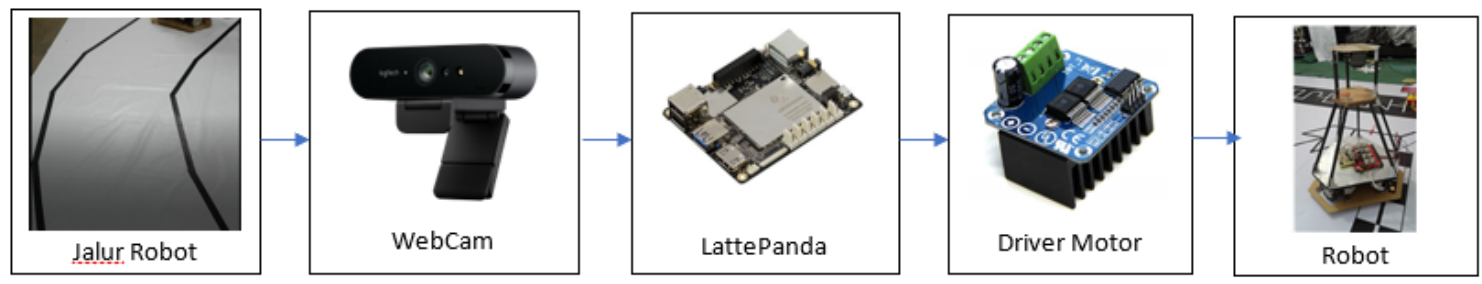

Gambar 3. Alur Proses dari Perangkat Keras Robot

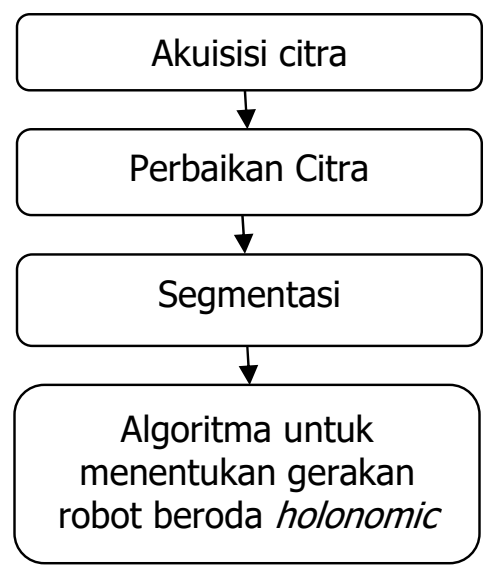

Gambar 4. Alur Proses dari Algoritma Pengolahan Citra 


\subsection{Robot Beroda Holonomic}

Robot yang digunakan adalah robot berjenis robot beroda dengan gerakan holonomic, robot jenis tersebut menggunakan roda omni, robot mampu bergerak ke arah sumbu $\mathrm{x}$ dan y secara bebas, dan memiliki tiga roda penggerak (McComb, 2011), ukuran dan bentuk robot ditunjukkan pada Gambar 5, robot tersebut memiliki ukuran tinggi $76 \mathrm{~cm}$, lebar $52 \mathrm{~cm}$, dan panjang $60 \mathrm{~cm}$. Bagian atas robot terdapat kamera yang digunakan untuk melihat garis di depan robot. Informasi dari kamera diproses oleh sebuah algoritma pemrograman untuk mendapatkan nilai yang digunakan sebagai acuan untuk menggerakkan robot. Algoritma tersebut ditanam di dalam sebuah Single Board Computer yaitu LattePanda, LattePanda adalah sebuah komputer kecil yang telah terintegrasi dengan Arduino.

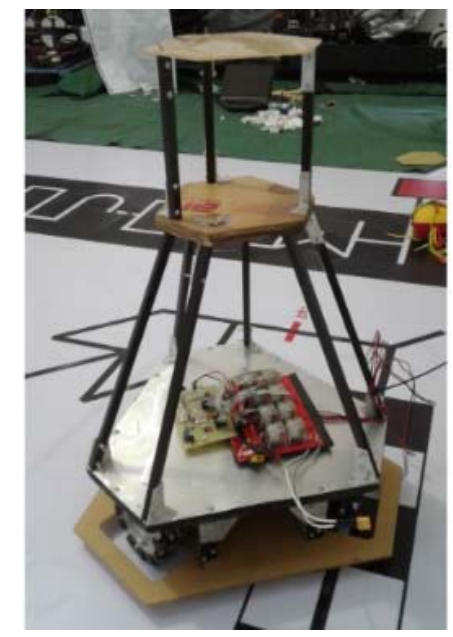

\section{Gambar 5. Robot Beroda Holonomic}

Robot bergerak akibat dari putaran motor DC, untuk mengatur kecepatan dan arah putar robot, diperlukan rangkaian driver motor (Gambar 6). Rangkaian pada Gambar 6 adalah rangkaian driver motor untuk satu motor, menggunakan komponen utama relai, kondisi saklar relai berubah akibat dari kondisi transisitor yaitu saturasi atau dalam kondisi cut off, perubahan kondisi saklar relai mengakibatkan arah putaran robot berubah. Sedangkan komponen FET pada rangkaian driver motor digunakan untuk mengatur kecepatan motor, kaki gate pada FET yang terhubung dengan optocoupler (U3) dihubungkan ke pin analog LattePanda. Sedangkan pin 1 pada optocoupler (U1 dan U2) digunakan pada pin output digital LattePanda.

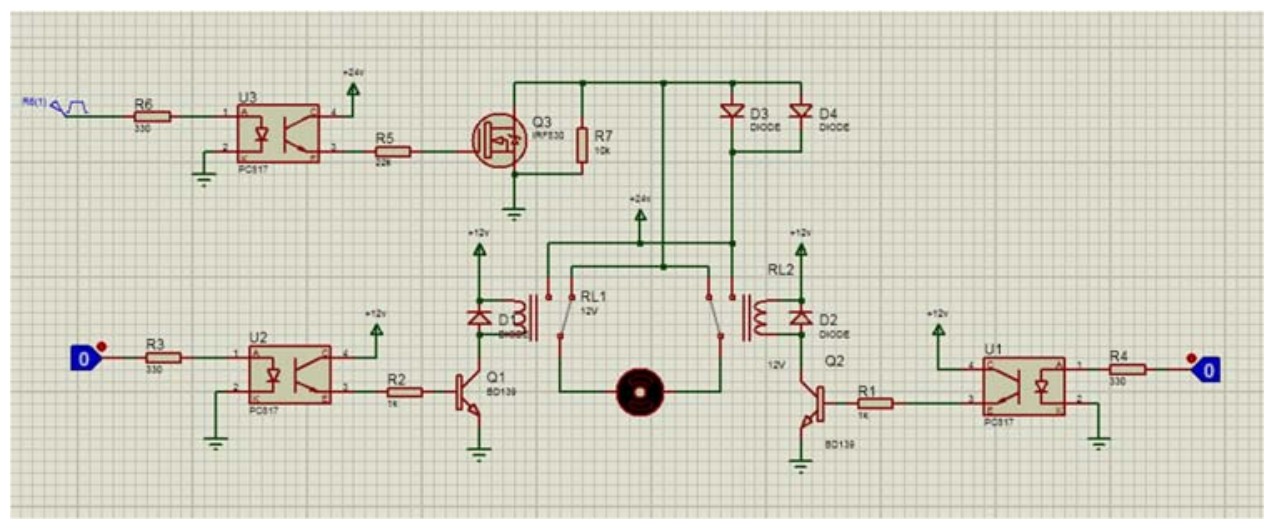

Gambar 6. Rangkaian Driver Motor 


\subsection{Perbaikan Citra}

Citra yang tertangkap tidak langsung diolah, diperlukan proses perbaikan citra terlebih dahulu. Setiap citra dimungkinkan terdapat derau yang berbentuk bintik-bintik, untuk mengurangi derau tersebut, tahap yang dilakukan adalah melakukan filter median menggunakan Persamaan (1), filter median berguna untuk menghilangkan bintik-bintik pada sebuah citra (Ramaraj \& Rajan, 2010).

$$
Y[x, y]=\operatorname{median}\left(I_{\text {orig }}[i, j], i, j \in \operatorname{nbor}[x, y]\right)
$$

Dengan:

$\mathrm{nbor}[\mathrm{x}, \mathrm{y}]=$ sub image dari citra RGB,

$\mathrm{I}_{\text {orig }}[\mathrm{i}, \mathrm{j}]=$ sebuah citra RGB

\subsection{Segmentasi}

Segmentasi adalah proses untuk memisahkan latar belakang dan latar depan citra. Untuk memisahkan latar belakang dan latar depan citra adalah dengan melakukan proses thresholding menggunakan Persamaan (2), nilai ambang diatur untuk memisahkan citra latar belakang dan latar depan, citra latar depan direpresentasikan dengan nilai pixe/ di setiap parameter RGB dengan nilai 255 (berwarna putih), sedangkan warna pixel citra latar belakang adalah berwarna hitam.

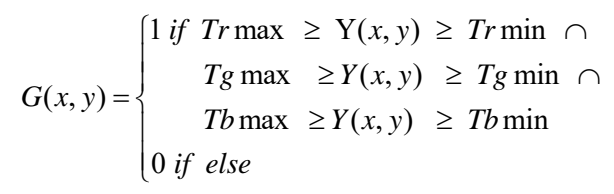

dimana $\mathrm{G}(\mathrm{x}, \mathrm{y})$ adalah image biner, $\mathrm{Y}(\mathrm{x}, \mathrm{y})$ adalah image $\mathrm{RGB}$, Trmax dan Trmin menyatakan nilai threshold maksimal dan minimal komponen $r$, Tgmax dan Tgrmin menyatakan nilai threshold maksimal dan minimal komponen $\mathrm{g}$, Tbmax dan Tbmin menyatakan nilai threshold maksimal dan minimal komponen $b$.

\subsection{Algoritma untuk Menentukan Gerakan Robot}

Setelah melakukan pemisahan latar belakang dan latar depan dari citra, tahap selanjutnya adalah melakukan pembuatan algoritma untuk mendapatkan jumlah pixel antara kolom tengah citra dengan garis pada citra, ilustrasi citra biner dan parameter yang digunakan untuk menentukan pergerakan robot ditunjukkan pada Gambar 7.

Nilai P_ka dan P_ki adalah nilai jumlah pixel antara garis kolom tengah citra dengan garis petunjuk navigasi robot. Nilai $P_{-}$ka adalah jumlah pixe/ sebelah kanan dan P_ki adalah jumlah pixe/ sebelah kiri. Jumlah pixe/tersebut diperoleh di baris pixe/ke 50 . Berikut adalah listing program yang digunakan untuk mendapatkan parameter P_ka da P_ki:

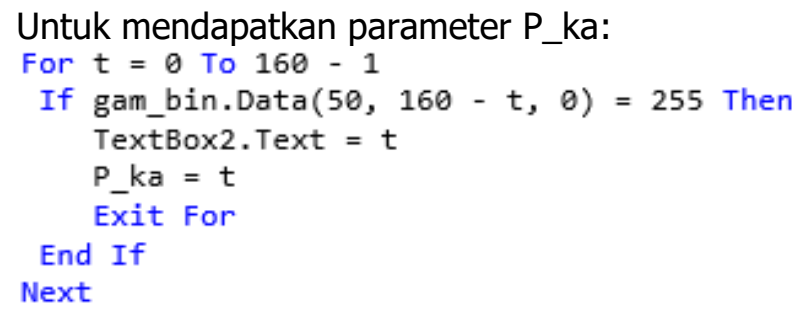



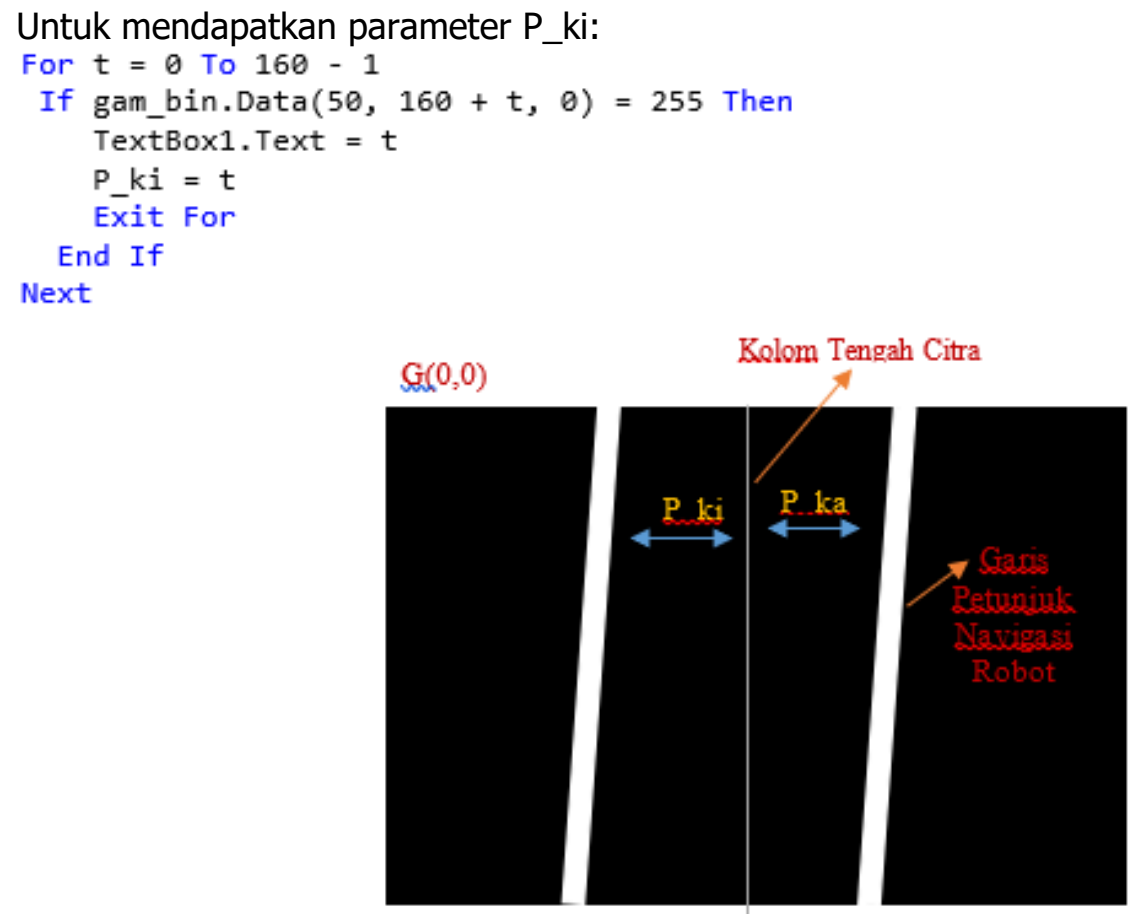

Gambar 7. Ilustrasi Sebuah Citra Biner Berukuran $320 \times 240$ dengan Parameter yang digunakan untuk Menentukan Pergerakan Robot

Setelah mendapatkan nilai P_ka dan P_ki, selanjutnya adalah mengirimkan nilai tersebut ke Arduino pada LattePanda untuk menggerakkan motor dc secara serial. Berikut adalah listing program untuk mengirimkan nilai dari parameter tersebut:

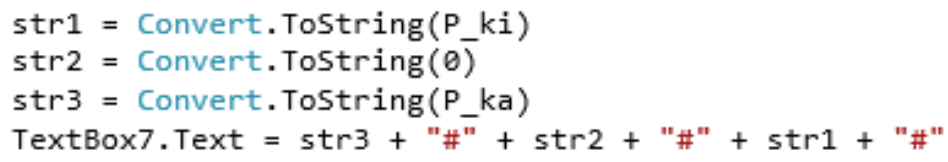

Sedangkan listing program untuk arduino yang telah menjadi satu board di Single Board Computer LattePanda adalah sebagai berikut:

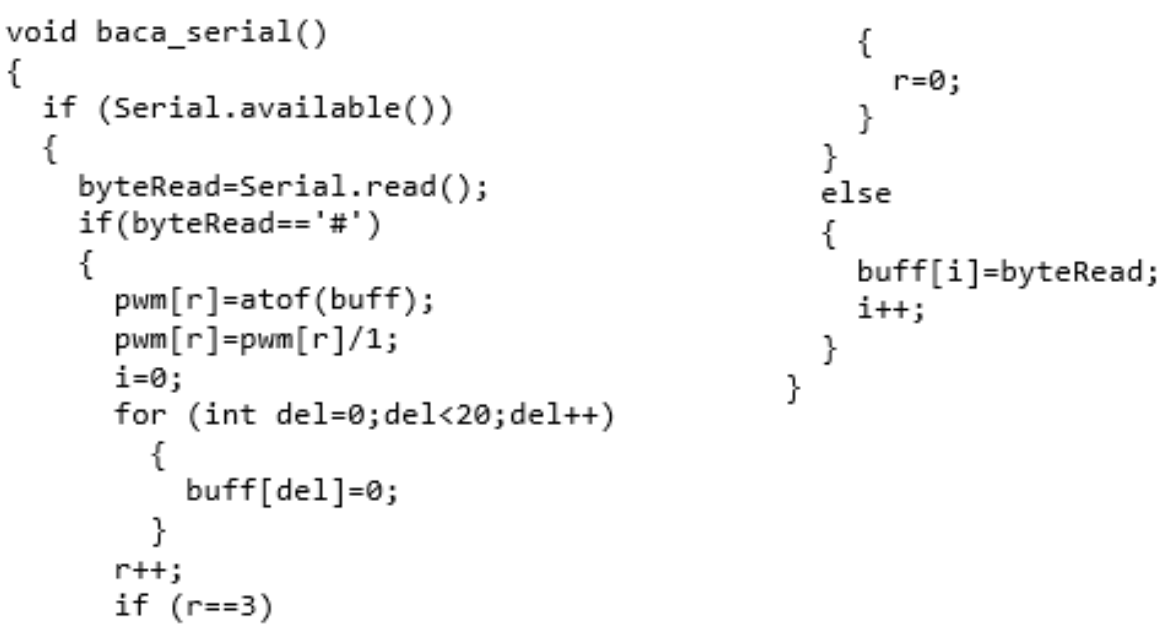


Setelah nilai diterima, selanjutnya adalah mengirimkan nilai tersebut ke driver motor dengan perintah:

analogWrite (5, pwm[0]);

analogWrite (3, pwm[1]);

analogWrite (6, pwm[2]);

\section{HASIL DAN PEMBAHASAN}

Ada beberapa tahapan pengujian dalam penelitian ini, yaitu pengujian pergerakan mobile robot holonomic, pengujian algoritma perangkat lunak, pengujian gerakan mobile robot holonomic pada sebuah jalur.

\subsection{Pengujian Pergerakan Robot Beroda Holonomic}

Pengujian ini dilakukan untuk mengetahui pergerakan robot terhadap nilai masukan yang berupa nilai analog dan digital dari mikrokontroler. Pergerakan robot yang dimaksud adalah maju, mundur, geser kanan dan kiri, putar kanan dan kiri, dan diam. Tabel 1 menunjukkan hasil dari pengujian. Dari tabel tersebut menunjukkan bahwa robot dapat melakukan gerakan-gerakan dasar berdasarkan keadaan nilai digital pada Port A dan analog pada pin 5, 3, dan 6. Pada saat robot berputar ke kanan dan ke kiri, nilai analog pada pin 5, 3, dan 6 sama, akan tetapi nilai pada port A berbeda, hal ini dikarenakan port A digunakan untuk mengubah arah putaran motor.

Tabel 1. Pengujian Gerakan Robot

\begin{tabular}{|c|c|c|c|c|}
\hline \multirow{2}{*}{$\begin{array}{c}\text { Port A } \\
\text { (Hex) }\end{array}$} & \multicolumn{3}{|c|}{ Pin Analog } & \multirow{2}{*}{$\begin{array}{c}\text { Pergerakan } \\
\text { Robot }\end{array}$} \\
\hline 0x0C & 200 & 0 & 200 & Maju \\
\hline $0 \times 03$ & 200 & 0 & 200 & Mundur \\
\hline $0 \times 86$ & 50 & 250 & 50 & Geser Kanan \\
\hline $0 \times 29$ & 80 & 250 & 80 & Geser Kiri \\
\hline $0 \times 26$ & 80 & 200 & 80 & Berputar kanan \\
\hline $0 \times 89$ & 80 & 200 & 80 & Berputar kiri \\
\hline $0 \times 00$ & 0 & 0 & 0 & Diam \\
\hline
\end{tabular}

\subsection{Pengujian Algoritma Perangkat Lunak}

Pengujian dilakukan menggunakan sebuah web cam, web cam digunakan untuk mengambil informasi citra jalur navigasi robot, citra yang digunakan untuk navigasi robot. Pengujian ini menggunakan sebuah kertas putih yang memilki dua garis warna hitam. Hasil dari pengujian dapat dilihat pada Tabel 2. 
Tabel 1. Pengujian Algoritma Pendeteksi Garis untuk Navigasi Robot

\begin{tabular}{|c|c|c|}
\hline Citra & P_ka & P_ki \\
\hline & 85 & 85 \\
\hline & & \\
\hline \\
\hline
\end{tabular}

Tabel 2 menunjukkan bahwa algoritma yang telah dibuat mampu mengenali baris navigasi robot, hal ini ditandai dengan area warna kuning, area warna kuning adalah area yang akan digunakan robot untuk menentukan pergerakan robot. Pergerakan robot ditentukan berdasarkan nilai P_ka dan P_ki, pada tabel terlihat bahwa ketika citra terlihat memiliki 
luasan area kuning pada sisi kanan dan kiri dari kolom tengah (garis warna biru muda) sama maka P_ka dan P_ki memiliki nilai 85, dan jika salah satu area warna kuning terlihat lebih sedikit dibandingkan lainnya, misalnya pada citra kedua pada tabel maka nilai P_ka $=148$ dan P_ki $=29$, dan begitu juga pada citra lainnya. Tentu hal ini menunjukkan bahwa algoritma yang telah dibuat memungkinkan untuk digunakan sebagai pengenal baris navigasi robot dan nilai $P_{-}$ka dan $P_{-}$ki dapat digunakan sebagai parameter untuk menentukan kecepatan penggerak robot. Nilai $P_{-}$ka digunakan untuk menentukan kecepatan roda kiri robot, sedangkan nilai P_ki digunakan untuk menentukan kecepatan roda kanan robot.

\subsection{Pengujian Gerakan Robot Beroda Holonomic pada Sebuah Jalur}

Pengujian dilakukan untuk mengetahui respon robot terhadap jalur yang telah disiapkan berdasarkan algoritma yang telah dibuat dan diuji sebelumya, Tabel 3 menunjukkan hasil pengujian.

Tabel 3 Pengujian Algoritma pada Robot

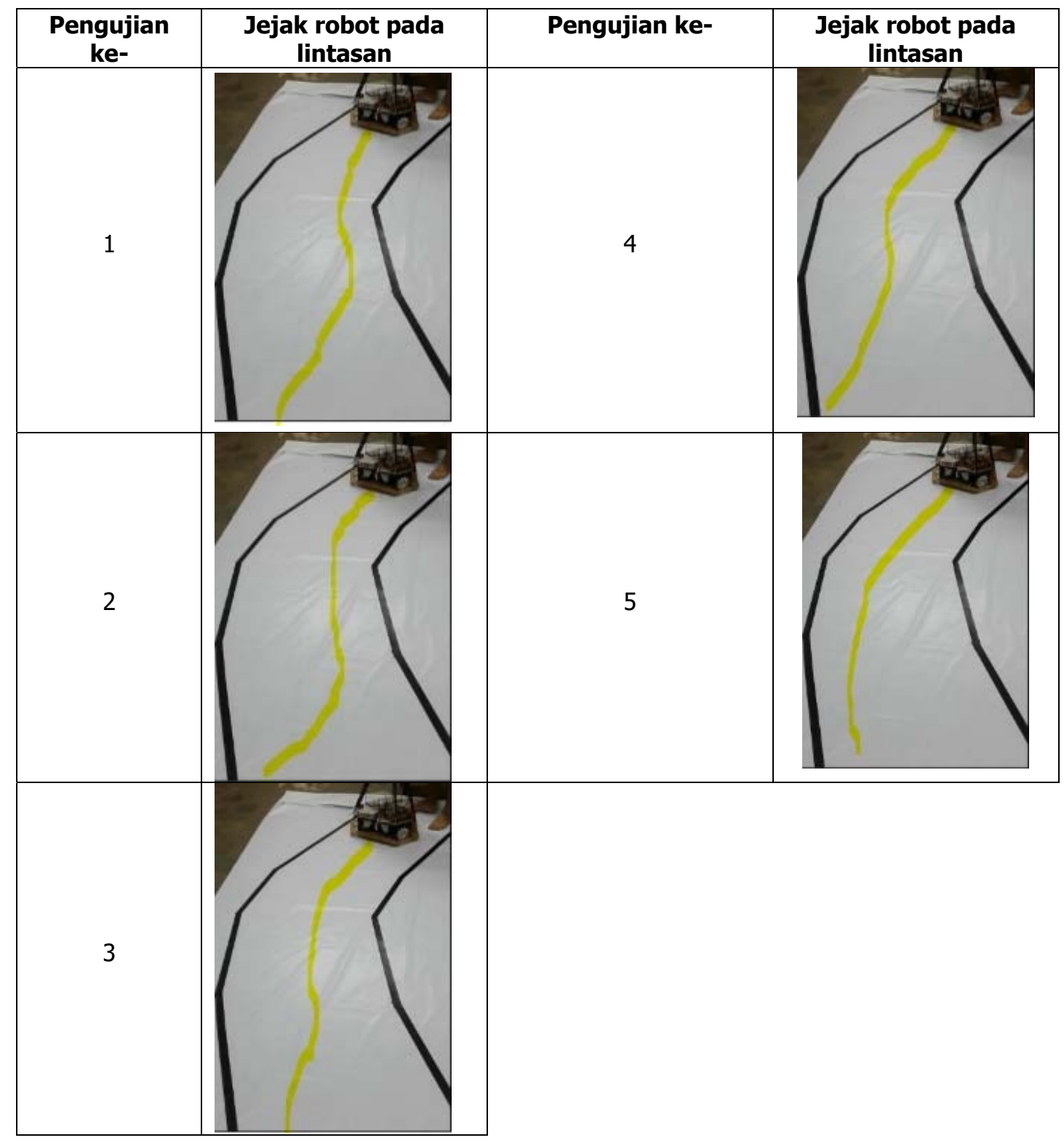


Pada Tabel 3 jarak antar garis pada jalur lintasan yang digunakan adalah $73 \mathrm{~cm}$. Pengujian dilakukan sebanyak 5 kali, pergerakan robot pada setiap pengujian direkam lalu diamati dan selanjutnya ditampilkan dalam sebuah tabel. Tabel 3 menunjukkan hasil pengujian algoritma pada robot, garis kuning pada gambar di tabel tersebut menunjukkan jejak pergerakan robot ketika bernavigasi. Dari tabel tersebut terlihat bahwa dari setiap pengujian jalur robot (warna kuning) tetap berada di dalam jalur antara dua garis warna hitam.

\section{KESIMPULAN}

Lane Tracking pada robot beroda holonomic menggunakan pengolahan citra telah dibuat. Driver motor yang diterapkan pada robot mampu menggerakkan tiga roda omni yang terpasang pada maing-masing motor DC. Rangkaian driver motor tersebut mampu menggerakkan motor DC searah dan berlawanan dengan arah jarum jam serta mampu mengatur kecepatan roda robot. Sehingga robot mampu bergerak tidak hanya maju, mundur, belok kanan dan kiri, akan tetapi mampu juga bergeser ke kanan dan ke kiri. Selain itu, algoritma pemrograman pengolahan citra yang telah dibuat mampu mengenali baris hitam dan jumlah pixe/ antara kolom tengah citra dengan garis warna hitam di sebelah kanan dan kiri dari kolom tengah citra. Sehingga hasil pengujian algoritma lane tracking pada robot menunjukkan bahwa robot mampu bernavigasi pada jalur yang ditentukan.

\section{DAFTAR RUJUKAN}

Bounini, F., Gingras, D., Lapointe, V., \& Pollart, H. (2015). Autonomous Vehicle and Real Time Road Lanes Detection and Tracking. IEEE Vehicle Power and Propulsion Conference (VPPC). Montreal: IEEE.

Chaidir, A. R., Muldayani, W., \& Kalandro, G. D. (2018). Pengenalan Gestur Jari Menggunakan Pengolahan Citra untuk Mengendalikan Joint pada Base Robot Lengan. Jurnal Rekayasa Elektrika, 14(3), 174-180.

Chaidir, A. R., Satriya, A. B., \& Kalandro, G. D. (2016). Design of a Gripping Imitator Robotic Arm for Taking an Object. 4th International Conference on Information and Communication Technology. Bandung: IEEE.

Fahmizal, Murti, B. B., \& Pratama, D. B. (2018). Kendali Logika Fuzzy pada Car Like Robot (CLMR) Penjejak Garis. ELKOMIKA, 6(3), 451-464.

Hassan, M. U., Ullah, M., \& Iqbal, J. (2016). Towards Autonomy in Agriculture: Design and Prototyping of a Robotic Vehicle with Seed Selector . International Conference on Robotics and Artificial Intelligence. Rawalpindi: IEEE, (pp. 37-44)

Ko, G., Oh, K.-H., \& Ahn, H.-S. (2016). Image-Based LAne Tracking in Quadcopter. IEEE 25th International Symposium on Industrial Electronics (ISIE). Santa Clara: IEEE, (pp. 387-392)

McComb, G. (2011). Robot Builder's Bonanza. New York: McGraw-Hill. 
Ramaraj, E., \& Rajan, A. S. (2010). Median Filter Using Open Multiprocessing in Agriculture. IEEE 10th International Conference on Signal Processing Proceedings. Beijing: IEEE.

Siciliano, B., \& Khatib, O. (2008). Springer Handbook of Robotics. Springer.

Umarkar, S., \& Karwankar, A. (2016). Automated Seed Sowing Agribot Using Arduino. International Conference on Communication and Signal Processing (ICCSP). Melmaruvathur: IEEE, (pp. 1379-1383)

Yoo, H., Yang, U., \& Sohn, K. (2013). Gradient-Enhancing Conversion for Illumination-Robust Lane Detection. IEEE Transactions on Intelligent Transportation Systems. IEEE, (pp. 1083-1094) 